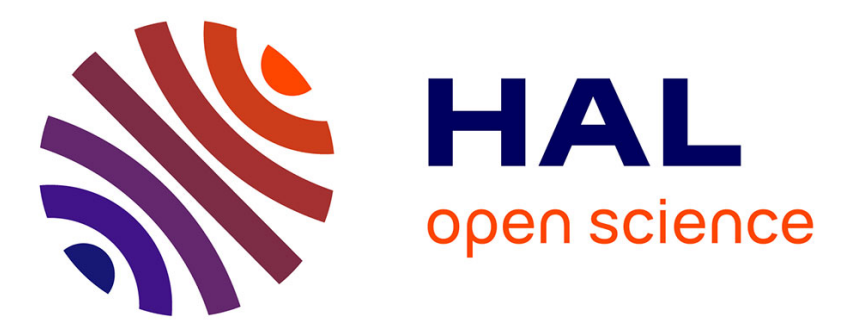

\title{
A Proposal of Order Planning Method with Consideration of Multiple Organizations in Manufacturing System
}

Ken Yamashita, Toshiya Kaihara, Nobutada Fujii, Daisuke Kokuryo, Toyohiro Umeda, Rihito Izutsu

\section{To cite this version:}

Ken Yamashita, Toshiya Kaihara, Nobutada Fujii, Daisuke Kokuryo, Toyohiro Umeda, et al.. A Proposal of Order Planning Method with Consideration of Multiple Organizations in Manufacturing System. IFIP International Conference on Advances in Production Management Systems (APMS), Sep 2019, Austin, TX, United States. pp.180-188, 10.1007/978-3-030-29996-5_21 . hal-02460462

\section{HAL Id: hal-02460462 \\ https://hal.inria.fr/hal-02460462}

Submitted on 30 Jan 2020

HAL is a multi-disciplinary open access archive for the deposit and dissemination of scientific research documents, whether they are published or not. The documents may come from teaching and research institutions in France or abroad, or from public or private research centers.
L'archive ouverte pluridisciplinaire HAL, est destinée au dépôt et à la diffusion de documents scientifiques de niveau recherche, publiés ou non, émanant des établissements d'enseignement et de recherche français ou étrangers, des laboratoires publics ou privés. 


\title{
A proposal of order planning method with consideration of multiple organizations in manufacturing system
}

\author{
Ken Yamashita ${ }^{1}$, Toshiya Kaihara ${ }^{1}$, Nobutada Fujii ${ }^{1}$, \\ Daisuke Kokuryo ${ }^{1}$, Toyohiro Umeda ${ }^{2}$ and Rihito Izutsu ${ }^{2}$ \\ ${ }^{1}$ Graduate School of System Informatics, Kobe University, \\ 1-1 Rokkodai-cho, Nada, Kobe, Hyogo 657-8501, Japan \\ yamashita@kaede.cs.kobe-u.ac.jp, kaihara@kobe-u.ac.jp, \\ nfujii@phoenix.kobe-u.ac.jp, kokuryo@port.kobe-u.ac.jp \\ ${ }^{2}$ Kobe Steel, Ltd., 1-5-5 Takatsukadai, Nishi, Kobe, Hyogo, 651-2271, Japan \\ umeda.toyohirodkobelco.com, izutsu.rihito@kobelco.com
}

\begin{abstract}
Manufacturing system includes multiple business organizations having different decision criteria such as factories, salespersons and customers. It is important to maximize the overall profit while considering the objectives of each organization by appropriate adjustment. In this study, we propose the order planning method using the credibility about salespersons. This proposed method adjusts the due date between the salesperson and the customer by considering the margin time, and then derives effective production schedule by solving the optimization problem that minimizes the weighted sum of the tardiness from due date and makespan. Several computational experiments are conducted so as to evaluate the effectiveness of the proposed method.
\end{abstract}

Keywords: Manufacturing system, Order planning, Production scheduling.

\section{Introduction}

In manufacturing industries, the production style has shifted to high-mix lowvolume manufacturing production from small-mix high-volume production in order to respond to the consumers' needs flexibly [1]. As a result, the market objective has been changed into shortening due date and product life cycle [2]. In response to this situation, industries have to constantly introduce new products to the market, and at the same time establish a decision making mechanism that can respond to consumers' needs quickly. The issues are to reduce product inventory, shorten lead time, estimate due date accurately, launch new products rapidly, and manage individual specifications flexibly as mass customization [3]. In order to solve these problems, it is necessary to improve the production efficiency with rational production scheduling and to properly adjust the gap between the customers' needs and due date estimation by the sales department.

In the relevant researches, there is order acceptance and scheduling problem proposed by Guerrero and Kern [4]. This is defined as the joint decision of which orders 
to accept for processing and how to schedule them, and various studies have been conducted on this [5].

In this study, we propose an order planning method that performs determination of the due date and production scheduling in consideration of the relationship among customers, salespersons and factories. In the determination of the due date, the response adjustment method by using sales department is used which gives margin time for the due date. In scheduling, we solve the optimization problem which minimizes the objective function using multiple indicators considering salespersons and factory managers. To evaluate the effectiveness of the proposed method, several computational experiments are performed.

\section{Target Model}

In this study, we target a factory model with multiple customers, salespersons and one factory as shown in Fig. 1. One ordering period is defined as lead time from customer's inquiry to delivery. Each business organization is set as follows.

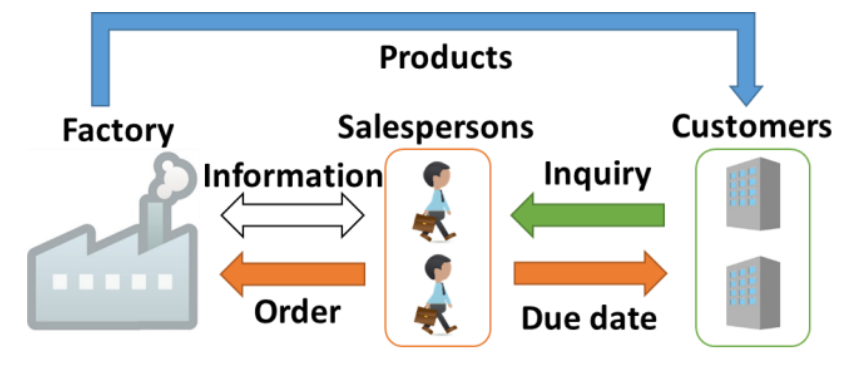

Fig. 1. Overview of relationship diagram among entities

\subsection{Customer}

Customers order the desired production item and the quantity of the items to the salespersons. Each customer has a degree of credibility to the salespersons which represent the previous order conditions. The order quantity is determined by the degree of credibility and the answered due date from the salesperson. The degree of credibility varies depending on the occurrence situation of the tardiness from the due date. When the credibility reaches the lower limit, the customer temporarily stops the transaction at the subsequent ordering period.

\subsection{Salesperson}

Salespersons make due date estimation in response to customers' order inquiries. Based on the desired due date of the customer and the information on the production schedule at the previous ordering period, the answered due date to the customer is decided in consideration with the margin time. By reducing the margin time, it is possible to bring the answered due date closer to the desired due date from the cus- 
tomers. On the other hand, the tardiness may increase. In contrast, by increasing it, occurrence of the tardiness can be decreased. However, the due date is far from the customers' desired due date.

\subsection{Factory}

The factory creates production schedule for the orders from salespersons per ordering period and manufactures products. This study targets multi-stage flow shops.

\section{$3 \quad$ Proposed order planning method}

The proposed order planning method in this study is explained. In this method, mainly due date adjustment and scheduling are performed. The algorithm of proposed method is described in Section3.2, and the formulation of factory scheduling within the algorithm is shown in Section 3.3.

\subsection{Notation}

The notations used in proposed order planning method are shown as follows:

$s:$ Salesperson $(s=1, \ldots, S)$

$c:$ Customer $(c=1, \ldots, C)$

$p:$ Order period $(p=1, \ldots, P)$

$O C:$ The number of time slots in one ordering period

$C R_{p, c}$ : Degree of credibility to salespersons by customer $c$ in period $p$

$B Q_{c}$ : Standard order quantity of customer $c$

$Q_{p, c}$ : Original order quantity of customer $c$ in period $p$

$Q_{p, c}^{\prime}:$ Final order quantity of customer $c$ in period $p$

$A T_{p, c}:$ Allowable time for order of customer $c$ in period $p$

$P D_{p, c}$ : Desired due date of customer $c$ in period $p$

$A D_{p, c}:$ Answered due date of the order of customer $c$ in period $p$

$C T_{p, c}$ : Correction time given order when the previous end time is later than the desired due date of customer $c$ in period $p$

$M T_{p, c, s}$ : Margin time given to order of customer $c$ in period $p$ by salesperson $s$

$D D_{p, c}:$ Delivery date of the order of customer $c$ in period $p$

$r_{Q D}:$ Rate of decrease in order quantity

$a_{C R I}:$ Amount of credibility increase when the order can be delivered within the answered due date

$r_{C R D}$ : Reduction rate of credibility at the time of the occurrence of the tardiness

In addition, the notations used in scheduling are shown as follows:

$j:$ Job number $(j=1, \ldots, J)$

$k:$ Stage number $(k=1, \ldots, K)$

$T_{p, j}$ : Tardiness of job $j$ in period $p$

$M S_{p}:$ Makespan in period $p$ 
$P T_{p, j, k}$ : Processing time of stage $k$ of job $j$ in period $p$

$S T_{p, j, j^{\prime}, k}$ : Setup time from job $j$ to job $j^{\prime}$ at stage $k$ in period $p$

$D_{p, j}$ : Due date of job $j$ in period $p$

$s_{p, j, k}:$ Start time of stage $k$ of job $j$ in period $p$

$E T_{p, j, k}:$ End time of stage $k$ of job $j$ in period $p$

$\alpha$ : Weight factor of objective function

$x_{p, j, j^{\prime}, k}:$ Decision variable

\subsection{Algorithm of proposed method}

In the proposed method using due date adjustment and production scheduling, the aim is to increase order quantity by reducing the tardiness and keeping the high credibility. The algorithm of the proposed method is expressed and the flowchart of the proposed method is shown in Fig. 2.

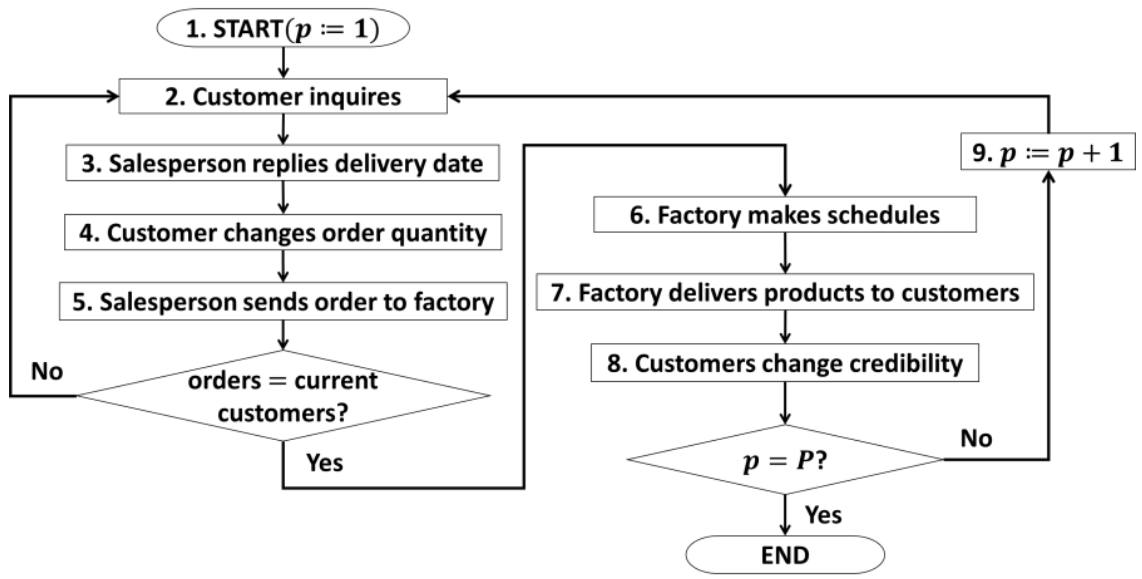

Fig. 2. Flowchart of proposed method

STEP1. Set the ordering period $p$ to 1 .

STEP2. The customer makes an inquiry about the order to the salesperson. Inquired order includes product type, desired order quantity $Q_{p, c}$ and desired due date $P D_{p, c}$ as information. The desired order quantity $Q_{p, c}$ is expressed by the following equation (1). The desired due date $P D_{p, c}$ is determined by the following equation (2).

$$
\begin{gathered}
Q_{p, c}=B Q_{c} \times C R_{p, c} \\
P D_{p, c}=(p-1) \times O C+A T_{p, c}
\end{gathered}
$$

STEP3. The salesperson estimates the due date for the order. When estimating, the salesperson obtains the end time of the schedule of the previous period from the factory. The answered due date $A D_{p, c}$ of the order of customer $c$ in period $p$ is expressed by the following equation (3).

$$
A D_{p, c}=P D_{p, c}+C T_{p, c}+M T_{p, c, s}
$$


STEP4. If the answered due date is later than the desired due date, the customer decreases the order quantity according to the tardiness. When the order quantity becomes 0 after the decreasing, the order is canceled. The final order quantity $Q_{p, c}^{\prime}$ is expressed by the following equation (4).

$$
Q_{p, c}^{\prime}=\max \left[0, Q_{p, c} \times\left\{1-r_{Q D} \times\left(C T_{p, c}+M T_{p, c, s}\right)\right\}\right]
$$

STEP5. The salesperson inserts the order to the factory. If STEP2 to STEP4 are performed by all the customers, the process proceeds to STEP6, otherwise, returns to STEP2.

STEP6. The factory divides the orders input in STEP5 into multiple jobs and formulates as a multi-stages flow shop scheduling problem. It creates a production schedule by solving the problem and manufactures products. This study uses IBM ILOG CPLEX 12.6.3 [6] to solve the problem.

STEP7. If the delivery date $D D_{p, c}$ of the order is included in the ordering period $p$, the factory delivers to the customer.

STEP8. If the order is in time for delivery, the credibility in the customer increases, and if the tardiness $d_{p, c}^{C R D}$ according to equation (5) occurs, the credibility decreases. Change in credibility $C R_{p, c}$ of customer $c$ in period $p$ is expressed by the following equation (6).

$$
C R_{p, c}=\left\{\begin{array}{cc}
d_{p, c}^{C R D}=\max \left(0, D D_{p, c}-A D_{p, c}\right), & \left(d_{p, c}^{C R D} \leq 0\right) \\
C R_{(p-1), c}+a_{C R I}, & \left(d_{p, c}^{C R D}>0\right)
\end{array}\right.
$$

STEP9. If $p$ period reaches the prescribed total number of times $P$, the process ends. Otherwise, $p:=p+1$ and return to STEP2.

\subsection{Formulation of $K$-stage flow shop scheduling}

The $K$-stage flow shop scheduling problem in STEP6 is formulated as follows as optimization problem:

$$
\begin{array}{cc}
\min & \alpha \sum_{\forall j} T_{p, j}+(1-\alpha) M S_{p} \\
\text { where } & T_{p, j}=\max \left(0, s_{p, j, k}+P T_{p, j, K}-D_{p, j}\right) \\
M S_{p}=\max _{\forall j, \forall k}\left(s_{p, j, k}+P T_{p, j, k}-E T_{p-1, k}\right) \\
E T_{p, k}=\max _{\forall j}\left(s_{p, j, k}+P T_{p, j, k}\right) \\
s_{p, j, k+1} \geq s_{p, j, k}+P T_{p, j, k} \\
\text { s.t. } \\
s_{p, j^{\prime}, k} \geq s_{p, j, k}+P T_{p, j, k}+S T_{p, j, j^{\prime}, k}\left(\text { if } x_{p, j, j^{\prime}, k}=1\right)\left\{\forall j, \forall j^{\prime}(\neq j), \forall k\right\} \\
s_{p, j, k} \geq E T_{p-1, k}(\forall j, \forall k) \\
s_{p, j, k} \geq 0 \\
x_{p, j, j^{\prime}, k}+x_{p, j^{\prime}, j, k}=1 \quad\left\{\forall j, \forall j^{\prime}(\neq j), \forall k\right\} \\
x_{p, j, j^{\prime}, k} \in\{0,1\} \quad\left\{\forall j, \forall j^{\prime}(\neq j), \forall k\right\}
\end{array}
$$

$x_{p, j, j^{\prime}, k}$ is the decision variable. When this value is 1 , job $j$ at stage $k$ in period $p$ precedes the job $j^{\prime}$. When this value is 0 , job $j^{\prime}$ at stage $k$ in period $p$ precedes job $j$.

Objective function (7) is intended for minimizing the weighted sum of the total tardiness and makespan. The reason for using these two as an evaluation index is that 
salespersons and the factory try to respond to customers' requests and raising productivity. The parameter $\alpha$ is a weight between the total tardiness and the makespan in the objective function.

Equations (8), (9) and (10) are the definition of tardiness, makespan, and end time. Constraint (11) guarantees that next stage is started after the completion of previous stage. Constraint (12) limits the number of jobs that can be processed at one time. Constraints (13) and (14) represent that start time is after the end time of previous period. Constraint (15) ensures that precedence relation of jobs is either one way.

\section{Computational experiments}

In order to evaluate the influence of the weight parameter $\alpha$ of the objective function and the margin time $M T_{p, c, s}$ which is given by the salespersons in the due date determination, the computational experiments are performed. In Experiment 1, we perform the sensitivity analysis for $\alpha$ which is the weighting factor of the total tardiness and makespan. Experiment 2 evaluates the influence of $M T_{p, c, s}$. The evaluation criteria are as follows:

- TO : Total order quantity

- $D L$ : Average tardiness per order [TS]

- $A C$ : Average final credibility

- $S C$ : The number of setup

\subsection{Experimental conditions}

The experiments are performed with the following conditions:

- The number of customers $(C): 10$

- The number of salesperson $(S): 10$

- The number of ordering period $(P): 10$

- The number of time slots in each ordering period : $100[\mathrm{TS}]$

- The number of job stages $(K): 2$

- The number of product types : 2

- Setup time due to change of product type $\left(S T_{p, j, j^{\prime}, k}\right): 2[\mathrm{TS}]$

- Customer allowable time $\left(A T_{p, c}\right): 20 \leq A T_{p, c} \leq 100[\mathrm{TS}]$ (uniform random number)

- Standard order quantity of customer $\left(B Q_{c}\right): 10$

- Initial credibility of customer $\left(C R_{0, c}\right): 1.0$

- Range of credibility of customer $\left(C R_{p, c}\right): 0.0 \leq C R \leq 1.0$

- Rate of decrease in order quantity $\left(r_{Q D}\right): 0.04$

- Amount of credibility increase when the order can be delivered within the answered due date $\left(a_{C R I}\right): 0.1$

- Reduction rate of credibility at the time of tardiness occurrence $\left(r_{C R D}\right): 0.04$

- The number of trials : 20 
In these experiments, it is assumed that salespersons do not share information of orders of other customers, so the number of customers and salespersons are the same.

\subsection{Experiment 1: Comparison by objective function parameter $\alpha$}

In Experiment 1, we simulated by varying the parameter $\alpha$ used for the weighted sum of the objective function in $M T_{p, c, s}=0$. When $\alpha$ is increased, the weight for minimizing the total tardiness in the objective function increases. Whereas if it is decreased, the weight of the minimization of the makespan increases. The results when $\alpha$ is set to $0.1,0.5,0.9$ are shown in Table 1 . Considering the results in Table 1, when the weight of the total tardiness increased, the average tardiness $D L$ was reduced. And when we increased the weight of makespan, the number of setup $S C$ decreased. From the result at $\alpha=0.9$, it was confirmed that increasing the weight of the tardiness raises the average final credibility $A C$ and the total order quantity $T O$.

Table 1. Results of Experiment $1\left(M T_{p, c, s}=0\right)$

\begin{tabular}{|c|c|c|c|c|}
\hline \multicolumn{2}{|c|}{} & $\alpha=0.1$ & $\alpha=0.5$ & $\alpha=0.9$ \\
\hline \multirow{2}{*}{$T O$} & Avg. & 635.07 & 666.11 & 669.37 \\
\cline { 2 - 5 } & S.D. & 45.68 & 49.39 & 43.00 \\
\hline \multirow{2}{*}{$D L$} & Avg. & 2.90 & 2.68 & 2.59 \\
\cline { 2 - 5 } & S.D. & 0.40 & 0.47 & 0.52 \\
\hline \multirow{2}{*}{$A C$} & Avg. & 0.64 & 0.70 & 0.73 \\
\cline { 2 - 5 } & S.D. & 0.08 & 0.08 & 0.09 \\
\hline \multirow{2}{*}{$S C$} & Avg. & 14.48 & 20.65 & 23.08 \\
\cline { 2 - 5 } & S.D. & 1.68 & 3.59 & 3.51 \\
\hline
\end{tabular}

\subsection{Experiment 2: Comparison by margin time $M T_{p, c, s}$}

In Experiment 2, we compared the simulation results at $\alpha=0.9$ with changing $M T_{p, c, s}$ given by the salespersons. Changes in $T O$ and $D L$ when $M T_{p, c, s}$ is 0 to 9 are shown in Fig. 3. Considering the results in Fig. 3, it was confirmed increasing margin time suppressed the tardiness. Also, TO was the maximum and increased more than when not having margin time in $M T_{p, c, s}=5$. So the effectiveness of the proposed method was confirmed. However, TO was decreased with increasing in margin time at $M T_{p, c, s} \geq 5$. Although the degree of credibility was increased by suppressing the tardiness, for order quantity, the influence of "decrease due to the difference between desired and answered due date" was larger than one of "increase due to high credibility". So the total order quantity was decreased. Therefore, in order to increase the order quantity, the appropriate adjustment of the margin time must be required. 


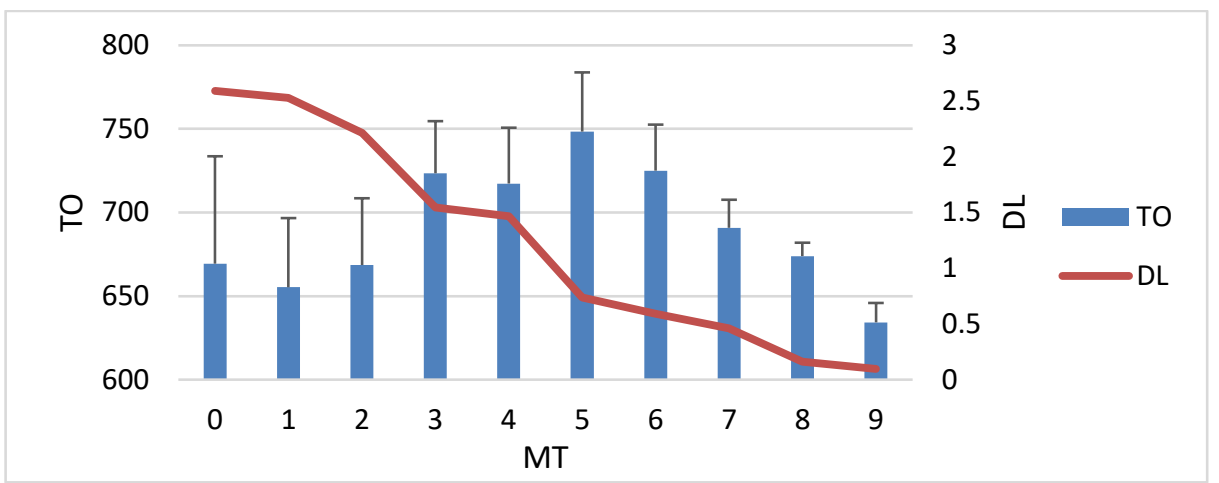

Fig. 3. Changes to $T O$ and $D L$ with various $M T_{p, c, s}(\alpha=0.9)$. Error bar: standard deviation

\section{Conclusion}

In this study, we targeted the manufacturing industry where there are multiple entities such as a factory, salespersons, and customers. And, the order planning method to decide due date including margin time and perform scheduling considering total tardiness and makespan was proposed.

In the computer experiments, we increased the weight for the total tardiness of the objective function in the scheduling problem and added the margin time to the due date. From the results, the tardiness from the due date was suppressed by them. Also, the proposed method was confirmed that the total order quantity increases as the margin time increases. However, in excessive margin time, the order quantity decreases due to being far from the customer's desired due date.

We will consider the adjustment method of the margin time as the next step.

\section{References}

1. Q. Zhang, M. M. Tseng. Modelling and integration of customer flexibility in the order commitment process for high mix low volume production. International Journal of Production Research, vol.47, issue 22. (2009).

2. Y. Nishioka. Synchronization technology for planning scheduling to respond quickly to changes in demand trends. Journal of the Society of Instrument and Control Engineers, vol.46, No.7, pp.529-534. (2007).

3. M. Kuroda. Delivery estimate and production scheduling - Information sharing and cooperation under the order production status-. Asakura Publishing. (2011).

4. H. H. Guerrero, G. M. Kern. How to more effectively accept and refuse orders. Production and Inventory Management, vol.29, issue 4, pp.59-62. (1988).

5. S. A. Slotnick. Order acceptance and scheduling: A taxonomy and review. European Journal of Operational Research, vol.212, issue 1, pp.1-11. (2011).

6. IBM Web page. http://www-01.ibm.com/software/commerce/optimization/cplexopitimizer 